\title{
Genetic and biological characteristics of recent Korean isolates of avian influenza virus subtype H9N2
}

\author{
Madhav Prasad Acharya ${ }^{1,3}$, Hyuk-Joon Kwon ${ }^{2}$, Il-Hwan Kim ${ }^{1}$, Youn-Jeong Lee ${ }^{4}$, Jae-Hong Kim ${ }^{1,2, *}$ \\ ${ }^{1}$ Laboratory of Avian Diseases, College of Veterinary Medicine, Seoul National University, Seoul 151-742, Korea \\ ${ }^{2}$ Research Institute for Veterinary Science, College of Veterinary Medicine and BK21 for Veterinary Science, \\ Seoul National University, Seoul 151-742, Korea \\ ${ }^{3}$ Animal Health Research Division, Nepal Agricultural Research Council, GPO Box 3733, Kathmandu, Nepal \\ ${ }^{4}$ Animal, Plant and Fisheries Quarantine and Inspection Agency, Anyang 430-757, Korea
}

(Received: October 12, 2012; Accepted: October 22, 2012)

\begin{abstract}
The worldwide distribution and continuing genetic mutation of avian influenza virus (AIV) has been posed a great threat to human and animal health. A comparison of 3 isolates of AIV H9N2, A/chicken/Korea/KBNP-0028/ 00 (H9N2) (KBNP-0028), A/chicken/Korea/SNU8011/08 (H9N2) (SNU 8011) and an inactivated oil vaccine strain A/chicken/Korea/01310/01 (H9N2) (01310), was performed. The former 2 AIVs were isolated from field cases before and after the application of an inactivated H9N2 vaccine in 2007, respectively. The antigenic relationship, viral shedding, tissue tropism and genetic analysis were examined. The comparison of virus shedding from the cloaca and the oropharynx revealed that both isolates were more frequently isolated from the upper respiratory tract $(90 \sim 100 \%) 1$ day post inoculation (DPI) compared with isolation 5 DPI from gastrointestinal tracts $(10 \sim 60 \%)$. Moreover, the isolate KBNP-0028 were recovered from all organs including bone marrow, brain and kidneys, indicating higher ability for broad tissue dissemination than that of SNU 8011. KBNP-0028 replicated earlier than other strains and with a higher titer than SNU 8011. In full-length nucleotide sequences of the NA gene and a partial sequence of the HA gene of SNU 8011, we found that there might be significant changes in tissue tropism, virus replication and genetic mutation in AIV H9N2 isolates.
\end{abstract}

Keywords : avian influenza, highly pathogenic avian influenza, low pathogenic avian influenza, stalk deletion

\section{Introduction}

Avian influenza (AI) is an acute, contagious, respiratory viral disease caused by the influenza virus. Among respiratory viruses, avian influenza viruses (AIVs) have unique features, with a segmented RNA genome and high antigenic diversity. Influenza viruses have been classified in three serotypes: A, B and C. Type A is responsible for the highly pathogenic avian influenza (HPAI) and worldwide human pandemics associated with severe morbidity and mortality. Influenza viruses infecting poultry can be divided in two groups. Highly pathogenic avian influenza (HPAI) can cause mortality as high as $100 \%$, while low pathogenic avian influenza (LPAI) causes disease in a milder form. However, LPAI may cause high mortality on occasion if concurrent infection with secondary pathogens occurs. All of the HPAI viruses to date belong to the $\mathrm{H} 5$ and $\mathrm{H} 7$ subtypes [32, 38, 39].

AIVs are enveloped, contain a single stranded, negative sense RNA genome containing 8 segmented genes and belong to the Orthomyxoviridae family [38]. The Influenza
A virus is classified into subtypes based on antigenic differences of the two viral surface proteins, hemagglutinin (HA) and neuraminidase (NA). To date, $16 \mathrm{HA}$ and 9 NA subtypes have been detected throughout the world, and type H16 was isolated in 1999 from black headed gulls in Sweden, which is the most recently isolated type [12]. All possible combinations of subtypes have been isolated from wild avian species. After continuous circulation of LPAI viruses of the subtypes $\mathrm{H} 5$ and $\mathrm{H} 7$ in chickens or other domestic birds, they can mutate into a highly pathogenic influenza A strain [3]. Influenza A viruses have been isolated from many species including humans, pigs, horses, mink, marine mammals and a wide range of domestic and wild birds. The virus comprises the subtypes $\mathrm{H} 3 \mathrm{~N} 8$ in equines and H1N1, H3N2 and H1N2 in swine. The HPAI virus was first isolated in Scotland in 1959 from chickens [38]. Waterfowls, shorebirds and gulls have been known as the main natural reservoirs of the influenza viruses. All influenza viruses infecting mammalian species originate from wild birds [39].

AIV subtype H5N1 has been focused on since it caused

*Corresponding author

Tel: $+82-2-880-1250$, Fax: $+82-2-885-6614$

E-mail: kimhong@snu.ac.kr 
severe disease problems worldwide in the poultry industry. Meanwhile, another challenge is the extensive spread of the LPAI virus subtype H9N2 in Asian and Middle Eastern countries since the virus' first detection in turkeys in Wisconsin, USA in 1966 [18]. In Asia, the subtype H9N2 virus has already been reported in Korea, China, Hong Kong, Saudi Arabia, India, Pakistan, Bangladesh, Nepal, Vietnam, Iran, UAE, Israel and Jordan [1-3, 26-29, 33].

In 1999 and 2003, the H9N2 virus was recovered from humans in Hong Kong [6]. Studies from China have reported that a novel genotype of AIV, the H9N2 influenza virus possessing human $\mathrm{H} 5 \mathrm{~N} 1$ internal genomes, has been circulating in poultry in eastern China [40]. In Korea, since the first report of LPAI outbreak in 1996, H9N2 viruses have become endemic, especially in layer and breeder chicken farms, which causes a severe decrease in egg production and mild to moderate mortality $[23,26]$. Therefore, the inactivated H9N2 oil vaccine has been used in that country since 2007 [8]. The application of the H9N2 vaccine has posed the threat of immune escape and subsequent mutation of H9N2 AIVs in the field. In this study, the antigenic relationship, biological variations and genetic changes of recent H9N2 isolates were examined and compared.

\section{Materials and Methods}

\section{Viruses}

The H9N2 isolates A/chicken/Korea/KBNP-0028/00 (H9N2) (KBNP-0028) and A/chicken/Korea/SNU8011/08 (H9N2) (SNU 8011) were examined. KBNP-0028 was a progeny virus of the field strain SNU 0028, which was generated by 20 passages in SPF embryonated chicken eggs (ECEs). SNU 0028 was isolated in 2000 from a diseased broiler breeder flock, and SNU 8011 in 2008 from a diseased layer breeder flock. An H9N2 vaccine strain, A/chicken/Korea/01310/01 (H9N2) (01310), was kindly provided by the Animal, Plant and Fisheries Quarantine and Inspection Agency. The AIVs were isolated and propagated by using 10-d-o SPF-ECEs as described previously [37]. The propagation was performed at $37^{\circ} \mathrm{C}$ for three days, the allantoic fluid was harvested and the aliquots were kept in $\mathrm{a}-70^{\circ} \mathrm{C}$ deep freezer until use. The titer was calculated according to a formula [36]. Subtyping for the isolates was carried out by reverse transcription polymerase chain reaction (RT-PCR) as previously described [11].

\section{Serology}

Hemagglutination inhibition (HI) and agar gel precipitation (AGP) tests were conducted following the previously described protocol [32]. Briefly, to determine the HA unit, $25 \mu \mathrm{L}$ of serial two-fold dilutions of antigen, with an equal volume of phosphate buffered saline (PBS, $7.2 \mathrm{pH}$ ) and $25 \mu \mathrm{L}$ of $1 \%$ chicken red blood cell (RBC), were added to each well in $\mathrm{V}$ shaped microtiter plates and incubated at room temperature for $40 \mathrm{~min}$. Likewise, for HI, a serial twofold dilution of $25 \mu \mathrm{L}$ of serum was performed with an equal volume of PBS ( $\mathrm{pH} 7.2$ ), and $25 \mu \mathrm{L}$ of 4 HA unit antigen was added to each well in a $\mathrm{V}$ shaped microtiter plate and incubated at room temperature for $30 \mathrm{~min}$. Then, $25 \mu \mathrm{L}$ of $1 \%$ chicken RBC was added to each well and again incubated for $40 \mathrm{~min}$. The HA titer was expressed as the reciprocal of the highest antigen/virus dilution that completely showed HA activities; whereas, the HI titer was expressed as the reciprocal of the highest dilution of serum that completely inhibited HA. For the AGP test, $1 \mathrm{gm}$ of purified agar (Sigma, Germany) and $8 \mathrm{gm}$ of sodium chloride (SHOWA, Japan) were dissolved in $100 \mathrm{~mL}$ 0.1 M PBS, pH 7.2 to make $100 \mathrm{~mL}$ agarose gel.

\section{Comparison of antigenicity}

The cross HI test was conducted using 4 HA units of the respective antigens. Antigens of the isolates KBNP-0028, 01310 and SNU 8011 were prepared by inactivation of the allantoic fluid with $0.1 \%$ formalin at $20^{\circ} \mathrm{C}$ for $10 \mathrm{~h}$. The positive sera were prepared by injecting the inactivated virus emulsified with oil adjuvant in $6 \mathrm{w}-\mathrm{o}$ SPF chickens. At three weeks after injection of the antigens, the chickens of each group were bled, and sera were obtained.

\section{Experimental design and challenge of chickens}

Two groups of 4-week-old (w-o) specific pathogen free (SPF) chickens (Hy-Vac, USA), with 10 chickens in each group, were housed in an isolator system (Three Shine, Korea). Each group of chickens was challenged with either of the H9N2 AIV isolates KBNP-0028 or SNU 8011 at a dose of $10^{6.5} 50 \%$ egg infective dose $\left(\mathrm{EID}_{50}\right) / 0.1 \mathrm{~mL} / \mathrm{bird}$ via the intranasal/ocular route.

\section{Re-isolation and titration of viruses}

Cloacal and oropharyngeal swabs were collected 1 day post-inoculation (DPI), 3 DPI and 5 DPI from each chicken. All the birds were sacrificed 5 DPI, and the bone marrow, brain, cecal tonsil, heart, kidney, lungs, spleen and trachea were collected aseptically, preventing cross contamination. All the swab samples were suspended in PBS ( $\mathrm{pH}$ 7.2) and treated with $1 / 10$ volume of $10 \mathrm{X}$ concentrated antibiotics and antimycotics. Similarly, the tissues were homogenized in $20 \%$ solution (weight/volume) using PBS, and then the same methods were applied as for swab samples. After centrifugation, the supernatant was inoculated in 10-d-o ECEs, and titration of the virus was performed.

\section{Extraction of viral RNA, RT-PCR and sequencing}

Viral RNA was extracted from infected allantoic fluid using the Viral Gene Spin, viral DNA/RNA extraction kit (iNtRON biotechnology, Korea), following the manufacturer's instruction. First strand cDNA synthesis was conducted using the SuperScript III First-Strand synthesis system for RT-PCR (Cat. No. 18080-051; Invitrogen, USA) using the Uni12 primer and was amplified using the gene specific primer sets according to the method described previously 
with a slight modification in the PCR conditions [17]. Amplified PCR products were analyzed by $1 \%$ agar gel electrophoresis. The products were purified using the PCRquickspin PCR product purification kit (iNtRON biotechnology) according to the manufacturer's instructions, and the concentration of the purified DNA product was determined by nanodrop spectrophotometer (Thermo Fisher Scientific, USA). Sequencing was carried out by direct sequencing of the purified PCR product using the respective primers in the ABI PRISM Big Dye Terminator cycle sequencing kits (Applied Biosystems, USA).

\section{Genetic and phylogenetic analysis}

Sequences were edited and aligned with the ClustalW method in MEGA software (ver. 4.0). The sequences of isolate SNU 8011 were compared to the H9N2 sequence data available from GenBank. The \% similarity and distance in nucleotide similarity analysis was performed using the National Center for Biotechnology Information (NCBI) BLAST program (USA), and the amino acid sequences were analyzed and the phylogenetic trees were constructed using the minimum evolution method. Bootstrap consensus trees were generated after the bootstrap test (500 repeats) using MEGA software (ver. 4.0). Prototype strains of the Asian lineage AIV subtype H9N2 were reproduced in phylogenetic trees for the purpose of comparison.

\section{Results}

\section{Biological characterization of $\mathrm{H} 9 \mathrm{~N} 2$ isolates}

Virus replication: The isolate KBNP-0028 showed earlier replication in 10-d-o ECEs, with a higher titer. The recent isolate SNU 8011 showed slower replication time and a lower HA titer than the other isolates. Although the vaccine strain 01310 did slow replication in embryos, the HA titer was equal to that of KBNP-0028 (Fig. 1). Furthermore, viral growth reached lag phase for all isolates at $20 \mathrm{~h}$ after inoculation.

Antigenic relationship among the isolates: The cross $\mathrm{HI}$ test showed a similar pattern of inhibitory reactions, indicating that the three H9N2 AIVs were antigenically similar (Table 1). Although, the recent isolate SNU 8011 showed marked HI titers of $9 \log _{2}$ with homologous and heterolo-

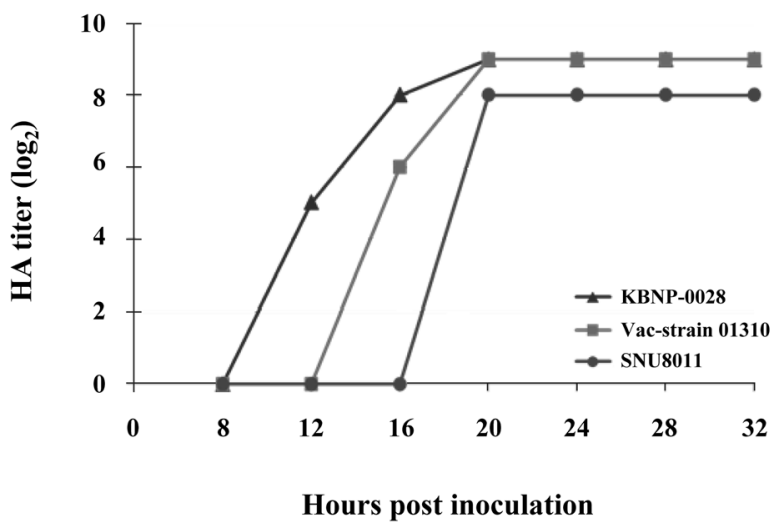

Fig. 1. Growth kinetics of three weakly pathogenic avian influenza virus subtypes of H9N2. Each virus was inoculated in 10day-old embryonated specific pathogen free eggs, and the hemagglutinin (HA) titers were determined every $4 \mathrm{~h}$ starting after the initial $8 \mathrm{~h}$. The inoculum of the virus was $10^{6.5} \mathrm{EID}_{50} /$ $0.1 \mathrm{~mL} / \mathrm{egg}$.

gous virus antigens, whereas the other two isolates showed limited reaction with heterologous antigens. Particularly, the vaccine strain 01310 showed a very weak HI reaction of the titer $4 \log _{2}$ with KBNP-0028.

Comparison of virus shedding and tissue tropism: Both AIV isolates were recovered from most of oropharyngeal swabs at 1 DPI to 5 DPI with higher HA titers than those from cloacal swabs (Table 2). In addition, at 5 DPI, the recovery rate was higher for both isolates along with a higher HA titer. The isolate KBNP-0028 was recovered from all

Table 1. Antigenic relationship among avian influenza viruses H9N2 by the cross HI test

\begin{tabular}{lccc}
\hline \hline & \multicolumn{3}{c}{ Avian influenza viruses } \\
\hline Anti-sera & KBNP-0028 & 01310 & SNU 8011 \\
KBNP-0028 & $256^{*}$ & 32 & 32 \\
01310 & 16 & 64 & 32 \\
SNU 8011 & 512 & 512 & 512 \\
\hline
\end{tabular}

*Hemagglutination inhibition (HI) antibody titers. Sera were obtained at two weeks after injecting formalin inactivated avian influenza viruses (AIVs) as antigen.

Table 2. Comparison of virus shedding after experimental infection with two avian influenza subtype H9N2 virus isolates in 4-weekold SPF chickens

\begin{tabular}{crccccc}
\hline \hline \multirow{2}{*}{ AIV Isolates } & \multicolumn{3}{c}{ OP swabs } & \multicolumn{3}{c}{ Cl swabs } \\
\cline { 2 - 7 } & 1 DPI & 3 DPI & 5 DPI & 1 DPI & 3 DPI & 5 DPI \\
\hline KBNP-0028 & $9 / 10^{*}$ & $10 / 10$ & $10 / 10$ & $1 / 10$ & $4 / 10$ & $6 / 10$ \\
SNU 8011 & $10 / 10$ & $10 / 10$ & $9 / 10$ & $1 / 10$ & $3 / 10$ & $5 / 10$ \\
\hline
\end{tabular}

SPF: specific pathogen free, OP swabs: oropharyngeal swabs, Cl swabs: cloacal swabs, DPI: days post inoculation. *Number shedding/ Number tested. Chickens were challenged with each AIV isolate. Inoculum of each virus was $10^{6.5} \mathrm{EID}_{50} / 0.1 \mathrm{~mL} / \mathrm{bird}$ by the intranasal/ocular route. 
Table 3. Recovery of avian influenza virus subtype H9N2 from different internal organs after experimental infection with each virus in 4-week-old SPF chickens

\begin{tabular}{llccccccc}
\hline \hline \multirow{2}{*}{ Isolates } & \multicolumn{7}{c}{ Internal organs } \\
\cline { 2 - 8 } & \multicolumn{1}{c}{$\mathrm{BM}$} & $\mathrm{Br}$ & $\mathrm{CT}$ & $\mathrm{Hrt}$ & $\mathrm{Kid}$ & $\mathrm{Lu}$ & $\mathrm{Sp}$ & $\mathrm{Tr}$ \\
\hline KBNP-0028 & $2 / 10^{*}(0)$ & $2 / 10(0)$ & $6 / 10(4.5)$ & $3 / 10(0)$ & $2 / 10(3.9)$ & $9 / 10(1.9)$ & $5 / 10(0.7)$ & $10 / 10(2.3)$ \\
SNU 8011 & $0 / 10(0)$ & $0 / 10(0)$ & $5 / 10(3.9)$ & $0 / 10(0)$ & $0 / 10(0)$ & $5 / 10(1.1)$ & $3 / 10(0.7)$ & $9 / 10(1.1)$ \\
\hline
\end{tabular}

SPF: specific pathogen free. Tissues; BM: bone marrow, Br: brain, CT: cecal tonsil, Hrt: heart, Kid: kidney, Lu: lungs, Sp: spleen, Tr: trachea. *Number of the virus isolation/number of the tested. Values in parenthesis are the viral titer from each of the pooled tissues, expressed as $\log _{10} \mathrm{EID}_{50} / 0.1 \mathrm{~mL}$.

Table 4. Similarity (\%) of HA and NA genes of isolate SNU 8011 and the other AI subtype H9N2 viruses

\begin{tabular}{ccccccc}
\hline \hline \multirow{2}{*}{ Gene } & \multicolumn{7}{c}{ AIVs } \\
\cline { 2 - 7 } & 01310 & Ck/Kor/MS96/96 & KBNP-0028 & Ck/Pk/2/99 & Qa/HK/G1/97 & Dk/HK/Y280/97 \\
\hline HA & 97 & 95 & 97 & 87 & 85 & 82 \\
NA & 99 & 96 & 93 & 85 & 87 & 88 \\
\hline
\end{tabular}

HA: hemagglutinin, NA: neuraminidase. A/chicken/Korea/01310/01 (H9N2), A/chicken/Korea/MS96/96 (H9N2), A/chicken/Korea/KBNP0028/00 (H9N2), A/chicken/Pakistan/2/99 (H9N2), A/duck/Hong Kong/Y280/97 (H9N2), A/quail/Hong Kong/G1/97 (H9N2).

Table 5. Difference in deduced amino acids of the HA gene and stalk deletion of the NA gene among AIV H9N2 viruses

\begin{tabular}{|c|c|c|c|c|c|}
\hline \multirow{2}{*}{ AIVs } & \multicolumn{3}{|c|}{ HA } & \multirow{2}{*}{$\frac{\text { NA }}{\text { Stalk deletion }}$} & \multirow{2}{*}{$\begin{array}{l}\text { Accession number } \\
\text { HA \& NA genes }\end{array}$} \\
\hline & $\mathrm{RBS}^{*}-226$ & Cleavage site & $158 \mathrm{~N}$-glycan & & \\
\hline SNU 8011 & Q & I-S-G-R & - & 24 & - \\
\hline KBNP-0028 & Q & A-S-G-R & + & 16 & EF620900-620902 \\
\hline 01310 & Q & A-S-G-R & + & - & EU253561-253562 \\
\hline $\mathrm{Qa} / \mathrm{HK} / \mathrm{G} 1 / 97$ & $\mathrm{~L}$ & R-S-G-R & - & 2 & AF156378-156396 \\
\hline $\mathrm{Dk} / \mathrm{HK} / \mathrm{Y} 280 / 97$ & $\mathrm{~L}$ & R-S-G-R & - & 3 & AF156376-156394 \\
\hline $\mathrm{Ck} / \mathrm{Pk} / 2 / 99$ & $\mathrm{~L}$ & R-S-S-R & - & - & AJ291392-291393 \\
\hline $\mathrm{Ck} / \mathrm{Bj} / 1 / 94$ & Q & R-S-S-R & - & - & AF156380-156398 \\
\hline
\end{tabular}

${ }^{*}$ RBS: Receptor binding site. The difference in amino acids at receptor binding site of hemagglutinin glycoprotein is associated with differences in the receptor binding specificity. The presence or absence of $158 \mathrm{~N}$-glycan in the vicinity of receptor binding sites on HA is associated with decreases or increases receptor-binding affinity, respectively.

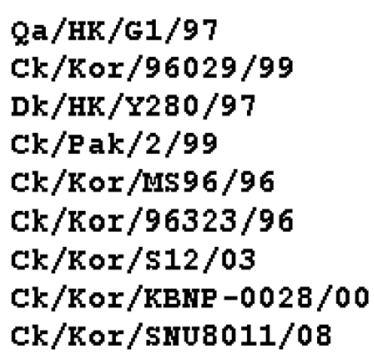

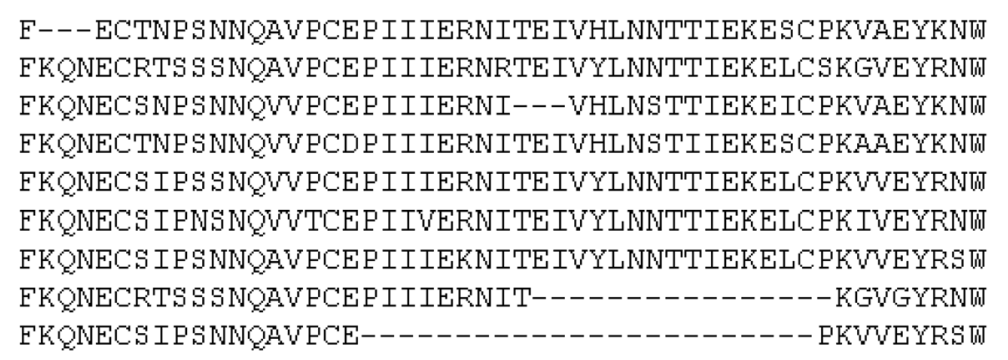

Fig. 2. Comparison of the deduced amino acid sequences at the neuraminidase (NA) stalk region among avian influenza virus (AIV) H9N2 strains. Deletion is indicated by dashes. Deletion of 2 amino acids in Qa/HK/G1/97, 3 (62-64) in Dk/HK/Y280/97, 16 (64-79) in $\mathrm{Ck} / \mathrm{Kor} / \mathrm{KBNP}-0028 / 00$ and 24 (54-79) in Ck/Kor/SNU8011/08.

tested tissues (Table 3): the bone marrow $(2 / 10,0)$, brain $(2 /$ $10,0)$, cecal tonsil $\left(6 / 10,10^{4.5} \mathrm{EID}_{50} / 0.1 \mathrm{~mL}\right)$, heart $(3 / 10,0)$, kidney $\left(2 / 10,10^{3.9}\right)$, lungs $\left(9 / 10,10^{1.9}\right)$, spleen $\left(5 / 10,10^{0.7}\right)$ and trachea $\left(10 / 10,10^{2.3}\right)$. In contrast, the isolate SNU 8011 was only recovered from the cecal tonsil $\left(5 / 10,10^{3.9} \mathrm{EID}_{50} /\right.$
$0.1 \mathrm{~mL})$, lungs $\left(5 / 10,10^{1.1}\right)$ spleen $\left(3 / 10,10^{0.7}\right)$ and trachea $\left(9 / 10,10^{1.1}\right)$. The virus titer in the cecal tonsil was found to be higher in both isolates. The titer from the kidney was also higher in KBNP-0028. Moreover, the isolate 8011 was not recovered from the bone marrow, brain, kidney or heart tis- 


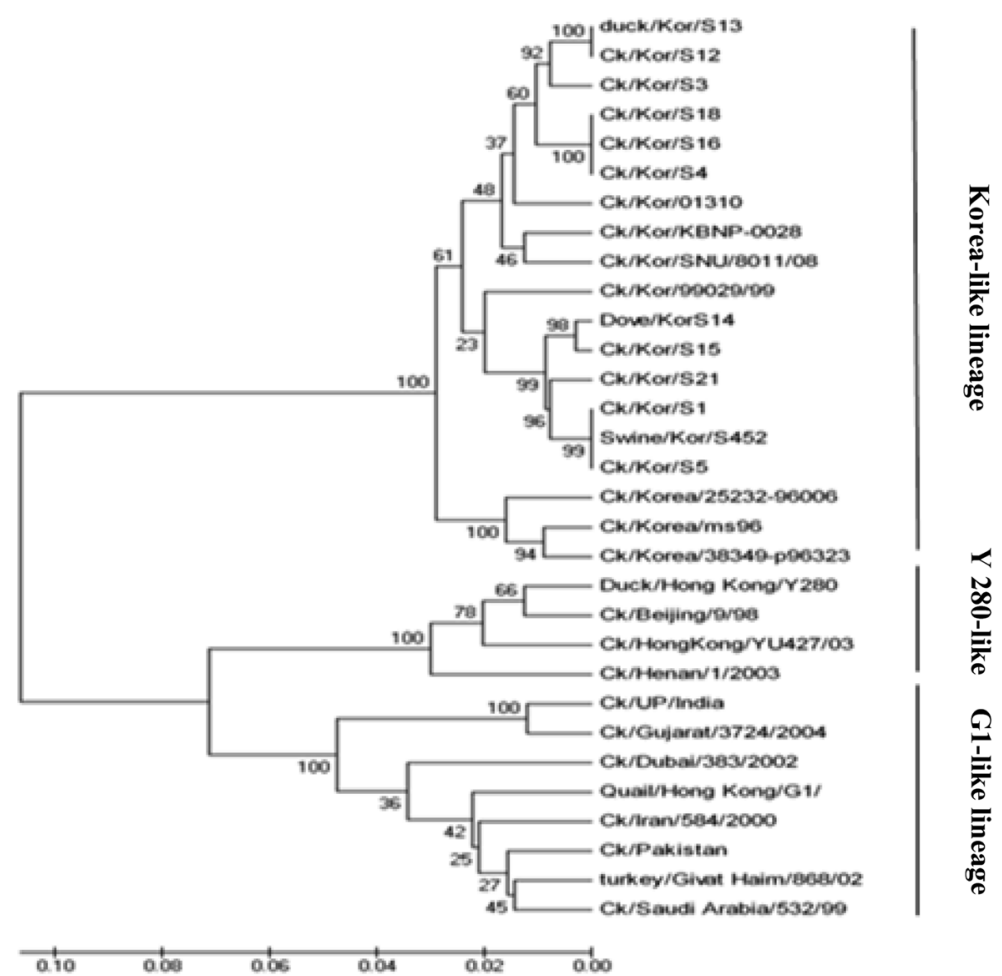

Fig. 3. Phylogenetic relationships among HA genes of AIV H9N2 strains. The Minimum Evolution method was used to construct trees, and the percentage of nucleotide differences is indicated by the scale. The bootstrap value with 500 replications and theTamura-Nei method were used for distance measurement. Isolate SNU 8011 compared with other AIVs, H9N2 sequences obtained from GenBank.

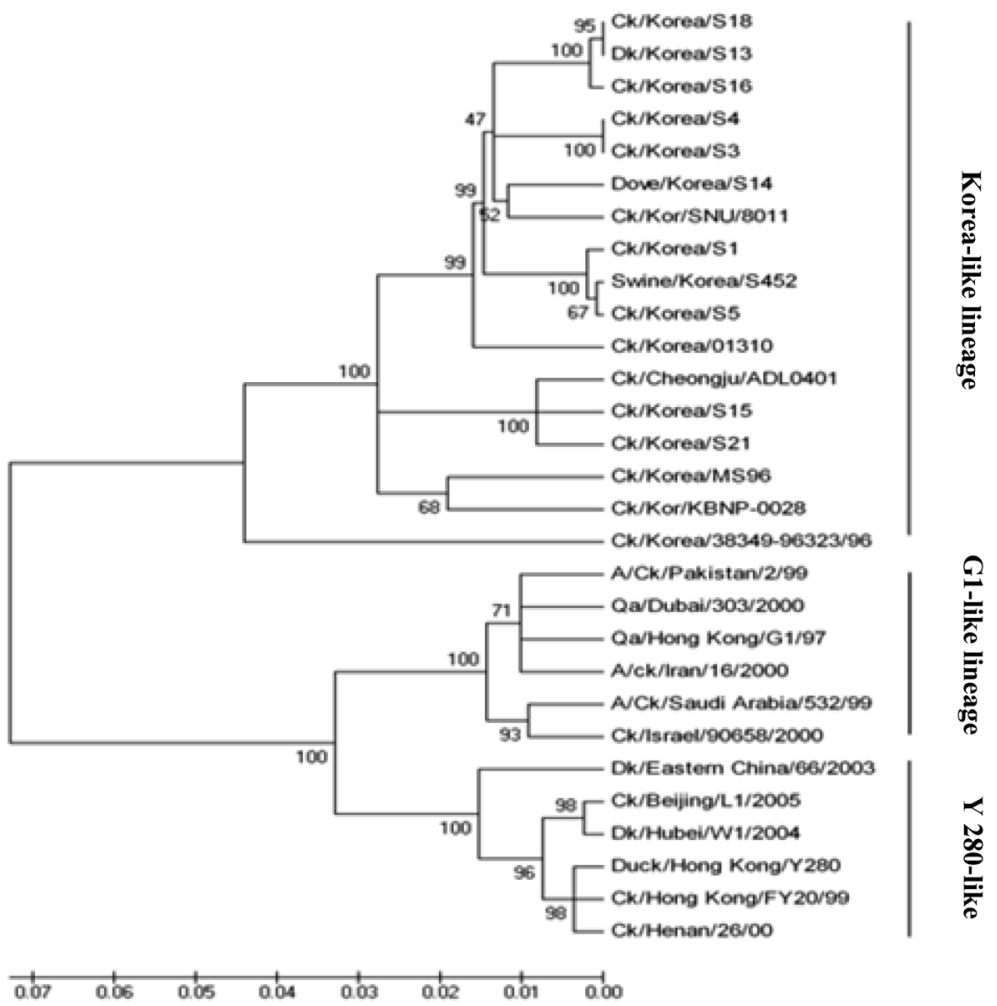

Fig. 4. Phylogenetic relationships of NA genes among AIV H9N2 strains. The Minimum Evolution method was used to construct trees, and the percentage of nucleotide differences is indicated by the scale. The bootstrap value with 500 replications and the Tamura-Nei method were used for distance measurement. Isolate SNU 8011 compared with other AIVs, H9N2 sequences obtained from GenBank. 
sues. Though the isolate KBNP-0028 was recovered from all tissue samples, the virus titer was very low in the bone marrow, brain and heart.

\section{Genetic and phylogenetic analysis of isolates to deter- mine viral mutation}

The nucleotide and amino acid sequences of the recent isolate SNU 8011 were compared with those of other H9N2 viruses, which are available in GenBank. The sequences of KBNP-0028, 01310, A/chicken/Korea/MS96/96 (H9N2) (Ck/ Kor/MS96/96), A/chicken/Pakistan/2/99 (H9N2) (Ck/Pk/2/99), A/quail/Hong Kong/G1/97 (H9N2) (Qa/HK/G1/97) and A/duck/ Hong Kong/Y280/97 (H9N2) (Dk/HK/Y280/97) were compared. The homology of the HA genes ranged from 82 to $97 \%$, and the homology of the NA genes ranged from 85 to 99\% (Table 4). The deduced amino acid sequences of the HA genes and the stalk deletion of NA genes were aligned and compared among H9N2 AIVs (Table 5). The recent isolate SNU 8011 has an HA cleavage site motif I-S-G-R, indicating low pathogenicity. The receptor binding site showed a $\mathrm{Q}$ at position 226, suggesting an avian-like receptor binding affinity, and the sequence demonstrated the absence of the $158 \mathrm{~N}$-glycan at the glycosylation site. In addition, the NA amino acid sequence showed a deletion of 24 amino acids (54-79) in the NA stalk region (Fig. 2).

SNU 8011 differed from KBNP-0028 and the vaccine strain 01310 in the absence of the $158 \mathrm{~N}$-glycan and the number of amino acids deleted in the NA stalk region. The HA cleavage site and receptor binding site at the HA amino acid position 226 were similar in all Korean isolates (Table 5). In the phylogenetic analysis of the HA and NA genes, the isolate SNU 8011 was well clustered (100\% bootstrap value) with Koreanlike lineage AIV H9N2 isolates. There were three distinct lineages among Asian AIVs: H9N2 strains (Figs. 3 and 4): the Korean-like, Y280-like and G1-like groups.

\section{Discussion}

LPAI caused by the AIV H9N2 is an economically important disease and remains a continuous threat to commercial poultry production worldwide; since the last decade, it has shown devastating effects in Asia, causing high mortality [27] and continuous evolution in domestic poultry [19, 20, 23].

In Korea, nationwide occurrences of LPAI caused by AIV H9N2 have been reported since the first outbreak of the disease in 1996 and have caused mild disease with up to $30 \%$ mortality in broiler breeder flocks [22]. To date, the disease has increased and has become endemic [21, 23]. Under certain conditions, Korean isolates have evolved causing 30\% mortality and a severe decrease in egg production in layers that were experimentally infected [19]. In addition, Korean AIV H9N2 isolates have shown continuous evolution, leading to the expansion of their host range to mammals, as well as an increasingly diverse gene pool among the AIVs isolated from live bird markets and domestic poultry as well [9, 23].
The isolate KBNP-0028, which was isolated in 2000, has demonstrated a case history of $30 \%$ mortality, with a marked decrease in egg production (data not shown), and the isolate SNU 8011 has caused less than $2 \%$ mortality and a moderate decrease in egg production under field conditions. However, in experimental infection in SPF chickens, neither mortality nor clinical illness was found. It has been frequently reported that secondary pathogens such as Escherichia coli, Staphylococcus aureus, Mycoplasma gallisepticum, Ornithobacterium rhinotracheale and the infectious bronchitis virus have played a significant role in aggravating the clinical condition of the birds infected earlier with AIV H9N2 [5, 13, 16, 25, 29]. It was also demonstrated that the complication of colibacillosis occurred during outbreaks caused by the isolate SNU 8011. In limited growth kinetic tests of the three isolates, they differed in replication time from one another, though the peak HA titer for all the isolates was reached at $20 \mathrm{~h}$ postinfection. In the antigenic analysis, the vaccine strain 01310 showed partial cross reactivity with heterologous isolates.

In the present study, virus recovery from oropharyngeal and cloacal swabs was $90 \sim 100 \%$ and $10 \sim 60 \%$, respectively, indicating that the viruses could more efficiently replicate in the respiratory tract than the digestive tract. Similar results have been reported from previous studies [8]. KBNP-0028 showed a wider range of tissue tropism and replicability. Although a low recovery rate $(2 / 10)$ and a higher viral titer $\left(10^{3.9} \mathrm{EID}_{50} / 0.1 \mathrm{~mL}\right)$ were observed in the kidney, the recent isolate SNU 8011 could not be recovered from the bone marrow, kidney, heart or brain. In a study reported in Pakistan, H9N2 AIV was re-isolated persistently from bone marrow following challenge infection [10], indicating marked biological variation among members of the same subtype.

Sequence comparison of the HA and NA genes of the recent isolate SNU 8011 showed a I-S-G-R cleavage site motif of HA, indicative of low pathogenicity. It represented restricted replication of the virus regarding infected cell types and the requirement of a trypsin-like enzyme for binding of the virus to susceptible cells. A higher percentage of homology of the HA amino acids to a vaccine strain 01301 (H9N2) was observed, but the NA amino acids showed higher similarity to KBNP-0028. However, there was a difference in the $158 \mathrm{~N}$-glycan at the glycosylation site of $\mathrm{HA}$ and in the length of the NA amino acid stalk region. SNU 8011 showed an absence of the $158 \mathrm{~N}$-glycan and a deletion of 24 amino acids in its NA stalk region, whereas both AIV KBNP-0028 and 01310 have $158 \mathrm{~N}$-glycan at their respective glycosylation sites. It has been reported that the presence of the N-glycans in the vicinity of the receptor binding site on the HA and the amino acid deletion in the stalk region of NA induced decreased receptor affinity and enzyme activities of the viruses [24, 31]. Interestingly, the isolate SNU 8011 showed high HA activity and replication in ECEs but was very weak in tissue tropism and replication compared with KBNP-0028. These distinctions could be due to differences in the combination of amino acid changes in the glycosyla- 
tion site and length of NA stalk region that directly affect the growth and spread of the virus in susceptible cells. An HA lacking the $158 \mathrm{~N}$-glycan at the HA glycosylation site combined with a long stalk NA or the presence of the $158 \mathrm{~N}$-glycan at the glycosylation site combined with a short stalk NA, may represent the optimal combination for viral growth [4].

Among Eurasian viruses, three distinct sub-lineages of H9N2 AIVs have been described, namely, Qa/HK/G1/97 (G1 group), Dk/HK/Y280/97 (Y280 group) and Ck/Kor/MS96/96 (Korea group) [12, 14, 15]. In a phylogenetic analysis of H9N2 AIV isolates, SNU 8011 showed well clustered HA and NA genes ( $100 \%$ bootstrap value) with the Korean-like lineage and showed $82 \%$ HA nucleotide homology with the $\mathrm{Dk} / \mathrm{HK} / \mathrm{Y} 280 / 97$ prototype strain and 85\% homology with the $\mathrm{Qa} / \mathrm{HK} / \mathrm{G} 1 / 97$ prototype strain Y280-like and G1-like groups, respectively. Likewise, the NA nucleotides showed $88 \%$ and $87 \%$ nucleotide homology with these prototype strains, respectively. Only the $95 \%$ and $96 \%$ homology of the HA and NA genes of SNU 8011 with the first Korean isolate $\mathrm{Ck} / \mathrm{Kor} / \mathrm{MS} 96 / 96$ indicated that H9N2 AIVs circulating in Korea also continue to evolve. The deduced amino acid at the receptor binding site was 226Q (avian like) in Korean isolates in comparison with 226L (human like) in Y280 and G1 prototype strains. An amino acid difference in the receptor binding sites of the HA glycoprotein is associated with differences in receptor binding specificity [25]. An HA protein that possesses an avian-like amino acid residue showed a preference for $\alpha$ 2,3-linked sialic acid moieties. Korean isolates as well as the Chinese isolate $\mathrm{Ck} / \mathrm{Bj} / 1 / 94$ have avianlike affinities, indicative of a low potential to infect humans. Despite the infection caused by subtype H9N2 in chickens, this subtype has been found to cause infection in humans [34], and evolution and isolation from other species has also been reported throughout Asia [7, 30, 35]. Furthermore, previous studies have shown that the $\mathrm{H} 5 \mathrm{~N} 1$ viruses were generated by the reassortment of genes [14], and H9N2 is one of the donors of the internal gene of the H5N1 subtype [5].

Korea has already faced the devastating effects of H5N1 HP AIVs, and during the last decade, the H9N2 virus has already been established [9]. Occasional cases of other serotypes of H9N8 [23] have been reported. In addition, recently it has been reported that H6N2 viruses of domestic poultry were separated into four genotypes by at least a triple reassortment between influenza viruses of low pathogenicity from Korean poultry (H9N2 and H3N2) and viruses from aquatic birds [20], which might be indicative of increases in the chance of more pathogenic strains to emerge through genetic assortments.

In conclusion, antigenic, biological and genetic diversities exist among the AI subtype H9N2 viruses isolated in Korea, and there may have been significant changes in the biological and genetic characteristics of AIVs H9N2 in the field. Therefore, intensive active surveillance of poultry farms and wild birds to monitor genetic mutation of the AIVs in circulation is very important.

\section{Acknowledgments}

This study was supported by a grant (Z-AD15-2010-11-02) from the Animal, Plant \& Fisheries Quarantine and Inspection Agency (QIA), Ministry of Food, Agriculture, Forestry and Fisheries, Republic of Korea, BK21 for Veterinary Science and Research Institute of Veterinary Science, Seoul National University, Republic of Korea.

\section{References}

1. Aamir UB, Wernery U, Ilyushina N, Webster RG. Characterization of avian H9N2 influenza viruses from United Arab Emirates 2000 to 2003. Virology 2007, 361, 45-55.

2. Al-Natour MQ, Abo-Shehada MN. Sero-prevalence of avian influenza among broiler-breeder flocks in Jordan. Prev Vet Med 2005, 70, 45-50.

3. Alexander DJ. A review of avian influenza in different bird species. Vet Microbiol 2000, 74, 3-13.

4. Baigent SJ, McCauley JW. Glycosylation of haemagglutinin and stalk-length of neuraminidase combine to regulate the growth of avian influenza viruses in tissue culture. Virus Res 2001, 79, 177-185.

5. Bano S, Naeem K, Malik SA. Evaluation of pathogenic potential of avian influenza virus serotype H9N2 in chickens. Avian Dis 2003, 47 (3 Suppl), 817-822.

6. Butt KM, Smith GJ, Chen H, Zhang LJ, Leung YH, Xu KM, Lim W, Webster RG, Yuen KY, Peiris JS, Guan Y. Human infection with an avian H9N2 influenza A virus in Hong Kong in 2003. J Clin Mirobiol 2005, 43, 5760-5767.

7. Chin PS, Hoffmann E, Webby R, Webster RG, Guan Y, Peiris M, Shortridge KF. Molecular evolution of H6 influenza viruses from poultry in southeastern China: prevalence of H6N1 influenza viruses possessing seven A/ Hong Kong/156/97 (H5N1)-like genes in poultry. J Virol 2002, 76, 507-516.

8. Choi JG, Lee YJ, Kim YJ, Lee EK, Jeong OM, Sung HW, Kim JH, Kwon JH. An inactivated vaccine to control the current H9N2 low pathogenic avian influenza in Korea. J Vet Sci 2008, 9, 67-74.

9. Choi YK, Seo SH, Kim JA, Webby RJ, Webster RG. Avian influenza viruses in Korean live poultry markets and their pathogenic potential. Virology 2005, 332, 529-537.

10. Ejaz R, Ahmed Z, Siddique N, Naeem K. Chicken meat as a source of avian influenza virus persistence and dissemination. Int J Poult Sci 2007, 6, 871-874.

11. Fereidouni SR, Starick E, Grund C, Globig A, Mettenleiter TC, Beer M, Harder T. Rapid molecular subtyping by reverse transcription polymerase chain reaction of the neuraminidase gene of avian influenza A viruses. Vet Microbiol 2009, 135, 253-260.

12. Fouchier RAM, Munster V, Wallensten A, Bestebroer TM, Herfst S, Smith D, Rimmelzwaan GF, Olse B, Osterhaus ADME. Characterization of a novel influenza A virus hemagglutinin subtype (H16) obtained from blackheaded gulls. J Virol 2005, 79, 2814-2822.

13. Gharaibeh S. Pathogenicity of an avian influenza virus 
serotype H9N2 in chickens. Avian Dis 2008, 52, 106-110.

14. Guan Y, Shortridge KF, Krauss S, Webster RG. Molecular characterization of H9N2 influenza viruses: were they the donors of the "internal" genes of H5N1 viruses in Hong Kong? Proc Natl Acad Sci USA 1999, 96, 9363-9367.

15. Guo YJ, Krauss S, Senne DA, Mo IP, Lo KS, Xiong XP, Norwood M, Shortridge KF, Webster RG, Guan Y. Characterization of the pathogenicity of members of the newly established H9N2 influenza virus lineages in Asia. Virology 2000, 267, 279-288.

16. Haghighat-Jahromi M, Asasi $\mathbf{K}$, Nili H, Dadras H, Shooshtari AH. Coinfection of avian influenza virus (H9N2 subtype) with infectious bronchitis live vaccine. Arch Virol 2008, 153, 651-655.

17. Hoffmann E, Stech J, Guan Y, Webster RG, Perez DR. Universal primer set for the full-length amplification of all influenza A viruses. Arch Virol 2001, 146, 2275-2289.

18. Homme PJ, Easterday BC, Anderson DP. Avian influenza virus infections. II. Experimental epizootiology of influenza A/Turkey/Wisconsin/1966 virus in turkeys. Avian Dis 1970, 14, 240-247.

19. Kim JA, Cho SH, Kim HS, Seo SH. H9N2 influenza viruses isolated from poultry in Korean live bird markets continuously evolve and cause the severe clinical signs in layers. Vet Microbiol 2006, 118, 169-176.

20. Kim HR, Lee YJ, Lee KK, Oem JK, Kim SH, Lee MH, Lee OS, Park CK. Genetic relatedness of H6 subtype avian influenza viruses isolated from wild birds and domestic ducks in Korea and their pathogenicity in animals. J Gen Virol 2010, 91 (Pt 1), 208-219.

21. Kwon HJ, Cho SH, Ahn YJ, Kim JH, Yoo HS, Kim SJ. Characterization of a chicken embryo-adapted H9N2 subtype avian influenza virus. Open Vet Sci J 2009, 3, 9-16.

22. Lee CW, Song CS, Lee YJ, Mo IP, Garcia M, Suarez DL, Kim SJ. Sequence analysis of the hemagglutinin gene of H9N2 Korean avian influenza viruses and assessment of the pathogenic potential of isolate MS96. Avian Dis 2000, 44, 527-535.

23. Lee YJ, Shin JY, Song MS, Lee YM, Choi JG, Lee EK, Jeong OM, Sung HW, Kim JH, Kwon YK, Kwon JH, Kim CJ, Webby RJ, Webster RG, Choi YK. Continuing evolution of H9 influenza viruses in Korean poultry. Virology 2007, 359, 313-323.

24. Luo G, Chung J, Palese P. Alterations of the stalk of the influenza virus neuraminidase: deletions and insertions. Virus Res 1993, 29, 141-153.

25. Matrosovich MN, Krauss S, Webster RG. H9N2 influenza A viruses from poultry in Asia have human virus-like receptor specificity. Virology 2001, 281, 156-162.

26. Mo IP, Song CS, Kim KS, Rhee JC. An occurrence of non-highly pathogenic avian influenza in Korea. Avian Dis 2003, 47, 379-383.

27. Naeem K, Ullah A, Manvell RJ, Alexander DJ. Avian influenza A subtype H9N2 in poultry in Pakistan. Vet Rec 1999, 145, 560.

28. Nagarajan S, Rajukumar K, Tosh C, Ramaswamy V, Purohit K, Saxena G, Behera P, Pattnaik B, Pradhan HK, Dubey SC. Isolation and Pathotyping of H9N2 Avian Influenza viruses in Indian poultry. Vet Microbiol 2009, 133, 154-163.

29. Nili H, Asasi K. Natural cases and an experimental study of H9N2 avian influenza in commercial broiler chickens of Iran. Avian Pathol 2002, 31, 247-252.

30. Ninomiya A, Takada A, Okazaki K, Shortridge KF, Kida H. Seroepidemiological evidence of avian H4, H5, and $\mathrm{H} 9$ influenza A virus transmission to pigs in southeastern China. Vet Microbiol 2002, 8, 107-114.

31. Ohuchi M, Ohuchi R, Feldmann A, Klenk HD. Regulation of receptor binding affinity of influenza virus hemagglutinin by its carbohydrate moiety. J Virol 1997, 71, 8377-8384.

32. Office international des epizooties (OIE). Manual of diagnostic tests and vaccines for terrestrial animals. OIE, Paris, 2008.

33. Pant GR, Selleck PW. Surveillance for Avian influenza in Nepal 2004-2005. Avian Dis 2007, 51 (1 Suppl), 352-354.

34. Peiris M, Yuen KY, Leung CW, Chan KH, Ip PLS, Lai RWM, Orr WK, Shortridge KF. Human infection with influenza H9N2. Lancet 1999, 354, 916-917.

35. Perdue ML, Swayne DE. Public health risk from avian influenza viruses. Avian Dis 2005, 49, 317-327.

36. Reed LJ, Muench H. A simple method for estimating fifty percent endpoints. Am J Hyg 1938, 27, 493-497.

37. Shortridge KF, Zhou NN, Guan Y, Gao P, Ito T, Kawaoka Y, Kodihalli S, Krauss S, Markwell D, Murti KG, Norwood M, Senne D, Sims L, Takada A, Webster RG. Characterization of avian H5N1 influenza viruses from poultry in Hong Kong. Virology 1998, 252, 331-342.

38. Swayne DE, Halvorson DA. Influenza. In: Saif YM, Fadly AM, Glisson JR, McDougald LR, Nolan LK, Swayne DE (eds.). Diseases of Poultry. 12th ed. pp. 153-184, Blackwell, Ames, 2008.

39. Webster RG, Bean WJ, Gorman OT, Chambers TM, Kawaoka Y. Evolution and ecology of influenza A viruses. Microbiol Rev 1992, 56, 152-179.

40. Zhang P, Tang Y, Liu X, Liu W, Zhang X, Liu H, Peng D, Gao S, Wu Y, Zhang L, Lu S, Liu X. A novel genotype H9N2 influenza virus possessing human H5N1 internal genomes has been circulating in poultry in eastern China since 1998. J Virol 2009, 83, 8428-8438. 